\title{
DESCUIDADO EM SAÚDE E EM ENFERMAGEM
}

\section{CARELESSNESS IN HEALTH AND IN NURSING}

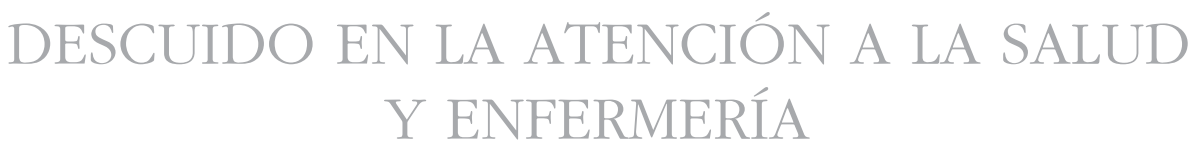

Fernanda Carneiro Mussi ${ }^{1}$

Cristina Maria Meira de Melo ${ }^{2}$

Como citar este artigo: Mussi FC, Melo CMM. Descuidado em saúde e em enfermagem. Rev baiana enferm. 2018;32:e25732.

Objetivo: refletir sobre o significado e as consequências do descuidado na atenção à saúde e em enfermagem. Método: estudo de reflexão. Resultados: o descuidado é produto do modelo assistencial biomédico, que privilegia o corpo como objeto de trabalho, fragmenta o processo de trabalho em saúde, exige prestação de serviços em larga escala com contenção de custos e não garante acesso ao atendimento universal, integral e igualitário. O usuário sofre por não ter assegurado o direito à vida, pela destituição da identidade e privação da satisfação na interação com trabalhadores em saúde. Consequências às trabalhadoras da enfermagem incluem identidade profissional ideologizada, perda do sentido e invisibilidade do trabalho e sofrimento psíquico. Conclusão: a reconstrução das práticas em enfermagem e na saúde, na perspectiva de combater o descuidado, pressupõe assumir o cuidado como cerne da formação e da prática nesse campo, além de investimentos no financiamento do SUS, para que seu projeto tenha o sucesso prático possível e esperado.

Descritores: Enfermagem. Cuidado. Atenção à Saúde.

Objective: reflect on the meaning and the consequences of carelessness in bealth care and in nursing. Method: reflective study. Results: the carelessness is a product of the biomedical care model, which privileges the body as an object of work, fragments the work process in health, requires service provision on a large scale with cost containment and does not guarantee access to universal, comprehensive and egalitarian care. The user suffers because the right to life is not guaranteed, due to the destitution of one's identity and the deprival from satisfaction in the interaction with health workers. Consequences for the nursing workers include linking professional identity to an ideology, loss of meaning and invisibility of the work and mental suffering. Conclusion: the reconstruction of the practices in nursing and health, from the perspective fighting the neglect, presupposes the assumption of care as the core of education and practice in this field, besides investments in the funding of SUS, so that its project can achieve the expected practical success potential.

Descriptors: Nursing. Care. Health Care.

Objetivo: reflexionar sobre el significado y las consecuencias del descuido en la atención a la salud y enfermería. Método: estudio de reflexión. Resultados: la desatención es producto del modelo asistencial biomédico, que privilegia el cuerpo como objeto de trabajo, fragmenta el proceso de trabajo en salud, exige prestación de servicios a gran escala con contención de costos y no garantiza acceso a la atención universal, integral e igualitaria. El usuario sufre por no haber asegurado el derecho a la vida, por la destitución de la identidad y privación de la satisfacción

\footnotetext{
Enfermeira. Doutora. Professora Associada IV da Escola de Enfermagem, Universidade Federal da Bahia. Líder do Grupo Interdisciplinar sobre o Cuidado à Saúde Cardiovascular. Salvador, Bahia, Brasil. femussi@uol.com.br

2 Enfermeira. Doutora. Professora Associada IV da Escola de Enfermagem, Universidade Federal da Bahia. Líder do Núcleo de Pesquisa em Política, Gestão, Trabalho e Recursos Humanos em Enfermagem e Saúde Coletiva. Salvador, Bahia, Brasil.
} 
en la interacción con trabajadores en salud. Consecuencias a las trabajadoras de la enfermería incluyen identidad profesional ideologizada, pérdida del sentido e invisibilidad del trabajo y sufrimiento psíquico. Conclusión: la reconstrucción de las prácticas en enfermería y en la salud, en la perspectiva de combatir el descuidado, presupone asumir la atención como núcleo de la formación y de la práctica en ese campo, además de inversiones en el financiamiento del Sistema Único de Salud, para que su proyecto tenga el éxito práctico posible y esperado.

Descriptores: Enfermería. Cuidado. Atención a la Salud.

\section{Introdução}

O cuidado profissional em saúde consiste "[...] na atenção à saúde imediatamente interessada no sentido existencial da experiência do adoecimento, físico ou mental, e, por conseguinte, também das práticas de promoção, proteção ou recuperação da saúde" ${ }^{, 1: 4}$. Portanto, o cuidado não é reduzível a razões e ações técnicas. O cuidado profisisonal consiste em "[...] conformação humanizada da atenção que visa a ampliação e flexibilização normativa das tecnociências da saúde na aplicação terapêutica"(1:22). Assim, o cuidado está relacionado com a interação intersubjetiva entre seres humanos, permitindo um encontro autêntico entre quem cuida e quem é cuidado, transcendendo o mundo físico e material. O cuidado profissional deve colocar a excelência das tecnologias à disposição da necessidade e da vontade do sujeito, na perspectiva de assegurar a vida com dignidade.

No ato de cuidar, o encontro terapêutico entre o profissional da saúde e o usuário deve permitir que o sentido instrumental das técnicas (o êxito técnico) esteja a serviço dos projetos elaborados em comum acordo com aqueles que buscam a atenção à sua saúde (seu projeto de felicidade). Somente nessa direção este encontro terapêutico resultará em sucesso prático ${ }^{(1)}$. No cuidado, o importante é permear a racionalidade técnica da atenção com os aspectos não técnicos que imprimem significado prático a sua aplicação. A possibilidade de articular o sucesso prático e o êxito técnico produzido num encontro terapêutico dá-se na dimensão dialógica, isto é, pela abertura de um autêntico interesse em ouvir aquele a quem queremos destinar nossas boas práticas profissionais, e ser por ele ouvido $^{(1)}$. Deste modo, o cuidado profissional é o resultado da sabedoria prática dos profissionais, amalgamado na atenção à saúde, cujo desafio é fazer "[...] coincidir toda ideia de sucesso prático com uma infinita busca de controle técnico" "2:69).

A perspectiva de cuidado assumida nessa reflexão é um desafio a ser alcançado nos cenários das práticas de saúde, dado que o modelo assistencial biomédico baseia-se numa racionalidade política, funcional e econômica que não permite o acesso universal ao Sistema Único de Saúde (SUS), mas exige a prestação de serviços em larga escala e com contenção de custos, o que impõe a organização fragmentada do processo de trabalho, por este ser executado por diferentes trabalhadores da saúde, entre os quais os profissionais de enfermagem. Esse modelo também dificulta ou impede o estabelecimento de vínculo entre profissionais/usuários e interfere na qualidade das ações e dos serviços prestados. Portanto, no cotidiano dos serviços de saúde, o descuidado é, significativamente, produto desse modelo. Este, por sua vez, é produto da ordem militar que reorientou a organização hospitalar no capitalismo, bem como do desenvolvimento da ciência e da técnica a serviço desse modo de produção econômico, cuja finalidade precípua é a recuperação do corpo como força de trabalho. Nesse sentido, é preciso recolocar em cheque o modelo assistencial hegemônico, refletindo sobre suas implicações na expressão do descuidado em saúde.

Com base no exposto, objetivamos, neste estudo, refletir sobre o significado e as consequências do descuidado na atenção à saúde e em enfermagem. 


\section{Método}

Trata-se de um estudo de reflexão teórica fundamentado na literatura consultada e na vivência das autoras. Assumimos uma concepção teórica sobre o cuidado em saúde/enfermagem e refletimos o desafio de ser alcançada nos cenários de atenção à saúde, devido ao modelo assistencial hegemônico, o qual pode produzir descuidado. Apresentamos a expressão do descuidado na atenção à saúde e enfermagem e depreendemos as suas possíveis consequências para as(os) trabalhadoras(es) em enfermagem, os usuários dos serviços de saúde e o próprio Sistema único de Saúde.

O artigo apresenta os dois elementos desta reflexão: Expressão do descuidado na atenção à saúde e em enfermagem; Consequências do descuidado na atenção à saúde e em enfermagem.

\section{Resultados e Discussão}

As seções seguintes abordam o descuidado na atenção à saúde e em enfermagem sob duas perspectivas: como produto do modelo biomédico hegemônico e suas consequências para trabalhadoras(es) em enfermagem, usuários/pacientes dos serviços de saúde e o próprio Sistema Único de Saúde.

\section{Expressão do descuidado na atenção à saúde e em enfermagem: produto do modelo biomédico hegemônico}

No modelo biomédico, o corpo doente é o objeto de trabalho em saúde e em enfermagem. Assim sendo, o ser humano atendido é apreendido numa perspectiva fisiopatológica, compreendido como um corpo mensurável, um arquétipo de valores normais, um conjunto de aparelhos, um corpo separado da psique, da emocão, do conhecimento, da história ${ }^{(3)}$. Assim, prevalece o uso de instrumentos de trabalho que atendam ao padrão técnico, racional, científico, normatizado e medido com base nos resultados produzidos. Desse modo, a intervenção em saúde é unidimensional, impositiva e limitada, constituindo-se no oposto do cuidado, que inclui competências e tarefas técnicas, mas não se restringe a elas. É claro que não se deve renunciar aos méritos da racionalidade técnica e científica para o cuidado, mas deve ser revista sua exclusividade como critério normativo para a obtenção do sucesso das práticas de saúde ${ }^{(2)}$.

Outro elemento que revela o descuidado como produto do modelo biomédico é a fragmentação do processo de trabalho em saúde e em enfermagem. Essa fragmentação afasta o trabalhador do cuidado e reforça a intervenção procedimental sobre o corpo máquina, ampliando a especialização e dificultando a articulação do trabalho em saúde, cuja natureza é coletiva. Nos serviços de saúde, desenvolve-se, em geral, um trabalho em equipe, e não em grupo, no qual cada profissional tem o seu conhecimento técnico específico como ferramenta necessária e suficiente para assistir ao corpo e suas patologias. O usuário é o receptor das ações técnicas, e o familiar, quando é considerado pelos profissionais, atua como mediador e/ou informante dos desvios fisiopatológicos do doente ${ }^{(4)}$ ou como sujeito capaz de conter as ações consideradas indesejáveis praticadas pelos mesmos profissionais.

Outro argumento para evidenciar que o descuidado é produto do modelo assistencial hegemônico é que a regência do modelo biomédico na organização do processo de trabalho em saúde e enfermagem afasta as trabalhadoras do cuidado e aproxima-as, na formação e na prática, da execução de procedimentos técnicos fragmentados. Destacamos que a institucionalização das práticas de saúde no modo de produção capitalista inseriu o médico no hospital moderno com a função de curar, pautada na relação dual profissional-paciente. Já a enfermeira é inserida nesse contexto organizacional como a profissional responsável pela organização e disciplina na prestação dos serviços de saúde, visando vigiar a recuperação do doente e assegurar a continuidade da prescrição terapêutica feita pelo médico ${ }^{(5)}$.

Nos primórdios do trabalho da enfermeira, a ação tanto da lady nurse quanto da nurse é 
direcionada para um corpo doente, e sua prática é caracterizada como subsidiária do saber- poder médico, centrada em uma rotina assistencial. A atuação da enfermeira é pautada no controle do ambiente, iluminação, higienização e aeração, controle das pessoas e dos tempos e movimentos - estabelecendo horário e ritmo de trabalho -, além do controle do processo de formação, de padrões de conduta moral e atuação profissional $^{(5)}$.

Hoje, embora enfermeiras diferenciem-se desse padrão de atuação, por encontrar ou criar brechas que permitem infrigir o modelo biomédico, este ainda é comum no campo da formação e das práticas em enfermagem. Com a institucionalização da prática da enfermeira, substitui-se o cuidado antes realizado no âmbito privado, como trabalho doméstico, pelas ações assistenciais exercidas no âmbito público, para atender demandas sociais concretas, dentre elas a do capital, por corpos aptos para o trabalho. Esta finalidade do capital determinou a organização do espaço hospitalar, do processo de trabalho e do lugar da enfermeira no trabalho em saúde.

Com o desenvolvimento e a crescente complexidade do conhecimento técnico e científico no campo da saúde, e as novas demandas da sociedade para a organização hospitalar, são agregados outros trabalhadores no campo da saúde. Consequentemente, ocorre a divisão social e técnica do trabalho em saúde, separando-se o trabalho entre ações consideradas como intelectuais e aquelas ditas manuais. Nessa divisão, o médico apropriou-se do trabalho intelectual, o que the conferiu um espaço de poder sobre os demais trabalhadores da saúde. Isso, somado ao avanço das tecnologias de diagnóstico e terapêuticas e ao aumento da demanda de usuários nos serviços de saúde, conduziu à produção de procedimentos controlados por protocolos. Essa divisão entre o trabalho intelectual e manual também atendeu à organização do processo de trabalho na lógica funcional e econômica, visando a produção de serviços médico-hospitalares em larga escala e com baixo custo.

A enfermeira, posicionada na função de articuladora e controladora do processo de trabalho em enfermagem, muitas vezes desenvolve uma relação de dominação sobre as auxiliares e técnicas por meio da divisão social e técnica do trabalho, com poderes que a diferenciam das suas subordinadas. Essa divisão técnica configura-se em acentudado parcelamento do trabalho em saúde e entre as categorias de trabalhadores. O trabalho em enfermagem pode estar centrado em tarefas e procedimentos (banho, sinais vitais, curativos, mudança de decúbito, sondagens, consultas, controle de materiais, gerenciamento do processo de trabalho, entre outros) distribuídos conforme a competência e qualificação da trabalhadora, sob orientação dos principios da administração científica, com a enfermeira atuando como coordenadora do processo de trabalho.

Tal processo revela-se na fragmentação das práticas assistenciais, reduzindo o usuário a condição de objeto passivo do trabalho das profisssionais, geralmente com uma única profissional encarregada de múltiplas tarefas direcionadas para um grande número de pacientes/usuários. Nesse modelo de organização do processo de trabalho em enfermagem, as interações intersubjetivas são dificultadas ou inviabilizadas e as trabalhadoras e usários são coisificados.

A atuação da enfermeira pode estar desviada da assistência e da gestão do processo de trabalho em enfermagem, que configuram atribuições fundamentais no cenário hospitalar e na atenção básica, para o cumprimento de funções meramente tecno-burocráticas. Estas não demandam competência técnica e científica e de relacionamento interpessoal e dificultam sua atuação na perspectiva do cuidado. Outras vezes, observamos que, devido às demandas da natureza do trabalho em enfermagem e ao número reduzido de trabalhadoras, a enfermeira desempenha inúmeras funções numa mesma jornada.

Ainda hoje, há uma tendência de a enfermeira abarcar a realização de procedimentos médicos, por entender que tais atribuições são uma forma de poder e reconhecimento profissional. As enfermeiras contribuem para manter o baixo valor de seu trabalho e a invisibilidade da sua profissão, ao negar ou desconhecer que, 
aceitando esse modo de atuar imposto pelas organizações de saúde, acentuam a divisão técnica do trabalho em saúde e em enfermagem.

No campo do ensino e da formação em enfermagem, é oportuno mencionar que existem escolas, ainda que embasadas nas diretrizes curriculares nacionais e em pedagogias nomeadas como ativas, vinculam ou enfatizam o aprendizado sobre o corpo científico, anatômico, biológico e doente. Especialmente nos cenários de práticas, o ensino veicula a imagem e o discurso de um corpo ideal, normativo, com uma estrutura e um modo de funcionamento específico, eliminando o corpo-desejo, corpo-prazer, corpo-estético e tantos outros não autorizados a se mostrar e serem mos$\operatorname{trados}^{(6)}$. Consequentemente, os instrumentos usados no ensino em enfermagem atendem ao cumprimento de um padrão técnico, com o cuidado reduzido à execucão humanizada (significando apenas um atendimento educado, respeitoso, menos distante ou menos "duro") de procedimentos técnicos.

Mesmo quando se identifica, no processo ensino-aprendizagem, o desenvolvimento de conhecimentos, saberes e práticas para aliar o êxito técnico a um sucesso prático, a enfermeira ingressante no mercado de trabalho precisa ajustar-se à "política de assistência" ditada pelos interesses das organizações, sejam elas de natureza pública ou privada, e dos seus empregadores. Ao pactuar com essa política institucional, a enfermeira também é coisificada e sofre pela impotência da sua prática. Para as enfermeiras conscientes dessa realidade, agrega-se o sofrimento por não conseguir transformar o cuidado em ações cotidianas.

Com base no exposto, a prática da enfermeira pode não se expressar pelo cuidado, mas sim por procedimentos assistenciais e gerenciais que, mesmo quando tecnicamente qualificados e "humanizados", nem sempre levam em conta o projeto de felicidade da pessoa/ família/grupos assistidos. São atos e procedimentos normativos, destituídos de uma atitude sensível de preocupação e responsabilização radical para com a experiência humana, com suas necessidades singulares de saúde e projeto de vida digna.

Ao mesmo tempo, identificamos, no processo de trabalho em enfermagem, considerando a dimensão psicológica, trabalhadoras em convívio com condições precárias, desgastantes e atemorizadoras de trabalho, dentre as quais salientamos: o impacto direto da doença física sobre os profissionais; a tentativa dos pacientes de compartilharem com a equipe sentimentos vivenciados de depressão, ansiedade, medo e repulsa pela doença; o contato com corpos mutilados, o sofrimento e a morte, além da execução de tarefas consideradas repulsivas, desgastantes e atemorizadoras ${ }^{(7)}$. No campo da atenção básica, essas profissionais estão expostas às desiguladades sociais, à violência institucional e de gênero, dentre outras condições. Este cenário conduz a enfermeira a exercer seu trabalho aproximando-se do controle e enquadramento de usuários e da equipe de enfermagem num padrão coercitivo e autoritário.

A natureza extremamente ansiogência do trabalho assistencial e gerencial da enfermeira acaba por fortalecer a divisão técnica do trabalho como uma estratégia de defesa psíquica. A enfermeira previne-se, assim, de entrar em contato direto com o paciente e, consequentemente, com a ansiedade dele decorrente ${ }^{(7)}$. A racionalização de sentimentos pela enfermeira é uma forma de perversão da razão. A divisão técnica do trabalho e os seus consequentes mecanismos de defesa psíquicos promovem também a fragmentação do relacionamento enfermeira-paciente/ usuário e do relacionamento enfermeira-demais trabalhadoras da enfermagem, além da despersonalização e negação da importância do sujeito. Em relação ao paciente/usuário, este passa a ser tratado não pelo nome, mas pelo número do leito ou pela doença ou órgão doente ou, como na atenção básica, pelo seu papel social de mãe, avó etc. ${ }^{(7)}$.

Pode ocorrer também a uniformização das condutas e dos doentes. Nesse caso, a maneira como um usuário é tratado é amplamente determinada pelo seu pertencimento a uma categoria de paciente e minimamente pelos seus desejos 
e necessidades idiossincráticos ${ }^{(7)}$. Citamos como exemplo a internação hospitalar, em que se observa usuários/pacientes serem despojados de pertences pessoais, submetidos a ritmos e tempos hospitalares (horário de banho, refeições e controles) e terem limitado o acesso ao familiar em razão de horários rígidos de visita, assim como às informações sobre a condução de seu tratamento, nem sempre asseguradas em razão de entraves na regulação na rede de serviços e limites na oferta do tratamento que deseja e necessita. Quando isso ocorre, usuários/ pacientes praticamente tornam-se propriedades das profissionais, deixando de ter família, de ser uma pessoa e ter uma identidade. Isso pode também ser revelado na atenção básica, quando predomina o trabalho da enfermeira dentro dos consultórios ou salas da unidade de saúde, lugar tradicional de poder, onde normas e condutas por vezes são ditadas pelo pertencimento do usuário a uma categoria de paciente (hipertenso, diabético, com hanseníase, aids, entre outras). Quando a enfermeira desloca-se para o território da comunidade, escola, domicílio, está exposta à realidade social com a qual nem sempre quer ou está preparada para lidar.

Outro mecanismo psíquico de defesa ocorre pelo distanciamento e negação de sentimentos, na utilização de mecanismos de escape do trabalho, meios pelos quais se inviabiliza qualquer possibilidade de continuidade de uma interação interpessoal e, portanto, do cuidado.

O descuidado expressa-se também por relações de poder evidenciadas no ritual de ajustamento dos usuários/pacientes e familiares às normas e rotinas institucionais, consideradas como invioláveis e incontestáveis, aplicadas sem discernimento. Este descuidado, que perpetua as relações tradicionais de poder, revela-se: no uso de linguagem científica, frequentemente impossibilitada de ser decodificada pelos usuários, representando um filtro social capaz de manipular a vontade desses; na falta de disponibilidade dos profissionais para a escuta; na negação ou postergação do atendimento de seus pedidos; na não pactuação com expectativas, limites e possibilidades da prosposta terapêutica ${ }^{(8-9)}$.
Ainda é preciso retomar a reflexão sobre o descuidado decorrente da concepção assistencial ditada pelas políticas e pelo modelo de organização dos serviços de saúde. Este descuidado caracteriza-se pelo que anteriormente chamamos de uma racionalidade política, funcional e econômica, que exige a prestação de serviços em larga escala e em alta velocidade, com contenção de custos e que não garante aos indivíduos o acesso ao atendimento universal, integral e igualitário ${ }^{(9)}$. Ou, como é comum no SUS, pelo descaso na implantação das políticas ou por escolhas políticas em fazer operar um sistema de serviços de saúde excludente.

$\mathrm{Na}$ atualidade, a racionalidade médico-científica diferencia-se e subordina-se cada vez mais à ordem tecnológica administrativa dos serviços de saúde, a qual dita as políticas de atendimento segundo padrões do mercado, mesmo no SUS $^{(9)}$. Um exemplo é o seu modelo de financiamento, com base na execução quantitativa de procedimentos ou por programas e projetos induzidos financeiramente pelo Ministério da Saúde. Nas organizações privadas, a assistência é considerada uma mercadoria que tem seu consumo determinado pelas leis de mercado e cujo acesso é proporcional ao poder aquisitivo dos consumidores.

Inseridas na lógica macroeconômica neoliberal, por meio da otimização de recursos, enxugamento da máquina, flexibilização do trabalho e várias outras medidas que devem redundar em aumento de receitas, as organizações de saúde prestam uma outra versão de "assistência". Os pacientes/usuários, quando conseguem ingressar no sistema de saúde, recebem uma assistência limitada pela decadência e abandono em que se encontram muitas dessas organizações. Subverte-se mais uma vez a perspectiva que deveria nortear toda e qualquer atividade voltada à saúde: a promoção do conforto e do bem-estar do ser humano ${ }^{(9)}$.

Nos serviços de saúde, o descuidado pode ser ilustrado pela impessoalidade do atendimento, as horas perdidas pelos usuários/paciente e acompanhantes em longas filas, seja a procura ou a espera por atendimento; pelas 
barreiras interpostas entre usuários e profissionais; o desespero de perceber a própria piora ou de seus familiares, sem ter acesso ao tratamento e sem entender o que se passa a seu redor ${ }^{(10)}$. Destacamos que a maioria dos usuários do SUS, quando acessa o serviço de saúde, submete-se à relação de quem presta atendimento e ao tratamento oferecido, com poucas possibilidades de escolha de profissionais e, via de regra, não possui as informações que o habilite a uma consciência sanitária capaz de julgar a capacidade técnica de quem o atende.

\section{Consequências do descuidado na atenção à saúde e em enfermagem}

Com base no exposto, é possível depreender consequências do descuidado para as(os) trabalhadoras(es) em enfermagem, para os usuários/ pacientes dos serviços de saúde e para o próprio Sistema Único de Saúde.

Como consequências do descuidado em relação à trabalhadora em enfermagem, que contribuem para que se sinta à deriva, sem controle sobre a sua vida e sobre a sua vida no trabalho, podemos apontar a identidade profissional ideologizada, com o lugar ocupado pela enfermeira como pouco visível e desvalorizado ${ }^{(11)}$; perda do sentido do trabalho, expresso no adoecimento e no sofrimento psíquico das trabalhadoras e não identidade com a profissão; múltiplos empregos; bem como as relações e condições precárias de trabalho instituídas pelo capitalismo neoliberal.

Para os usuários/pacientes, as consequências parecem visíveis no sofrimento para assegurar o direito à vida, submetido à logica econômica que impede ou dificulta o acesso ao sistema e aos serviços de saúde. O descuidado fruto do cenário assistencial vigente produz medo, ansiedade, desilusão e frustração de expectativas. Isso acontece pela incerteza, tempo de espera ou impossibilidade de acesso aos serviços de saúde e pela incerteza de lhe ser assegurada a qualidade técnica e a resolutividade do atendimento. A decepção pode ocorrer se constatar que o acesso ao sistema pouco significou para a sua qualidade de vida. Já o sofrimento existe pela destituição da sua identidade, pela desconsideração do humano, expressa na despersonalização, negação e categorização da importância das pessoas no modelo assistencial hegemônico; por não ser valorizada, pelos profissionais, a sua participação nas decisões; pela privação de satisfação positiva na interação com as trabalhadoras e os trabalhadores; pela falta de sentimento de consideração e desejo pelo seu bem-estar; pelo distanciamento e negação de suas necessidades; pela manipulação constante de corpos considerados como "dóceis e frios"(12).

Para o SUS, a consequência do descuidado aponta para a incompatibilidade do modelo biomédico e da racionalidade política, funcional e econômica dos serviços de saúde com os seus princípios. O financiamento insuficiente, a corrupção na gestão do sistema, o lento combate à exclusão na nossa sociedade e o predomínio de políticas neoliberais, mesmo na saúde, impedem que seu projeto tenha o sucesso prático possível e esperado.

\section{Conclusão}

Reconhecemos que são diversos os desafios para a reconstrução das práticas de saúde na perspectiva do combate ao descuidado. Reconhecemos a necessidade de investimentos públicos no financiamento do SUS e para que seu projeto tenha o sucesso prático possível e esperado. Entendemos que, mesmo no modo de produção econômico capitalista, e com a organização do processo de trabalho regido pelo modelo biomédico, as enfermeiras podem prestar cuidados e não apenas procedimentos técnicos, construindo brechas no cotidiano do trabalho e escapando dos dispositivos engendrados pelas instituições e organizações da saúde.

Reconhecemos a força propulsora do avanço do conhecimento em enfermagem, associado à conceptualização do cuidado nas teorias e pesquisas que evidenciam a superação dos limites da clínica enquanto saber fundamental. Entretanto, entendemos que ainda podemos avançar para a construção teórica no campo da enfermagem. Portanto, defendemos a construção da 
identidade profissional, dando visibilidade às três profissões e suas diferenças. Podemos iniciar por nomear apropriadamente as profissões de enfermeira, auxiliar e técnica de enfermagem que, na produção teórica brasileira não é incomum ser chamada de enfermagem. Procedendo assim, escamoteamos quem é, o que faz e como faz cada uma dessas profissões e as diferenças entre elas. Tal atitude nos afasta ainda mais da construção prática do cuidado profissional em enfermagem.

Compreendemos que a reconstrução das práticas em enfermagem e na saúde, na perspectiva de combater o descuidado, pressupõe assumir o cuidado como cerne da formação e da prática nesse campo. Apostar na possibilidade de um diálogo entre a tecnociência em saúde e as referências de usuários/família sobre o sucesso prático das ações em saúde, procurando conhecer o valor que essas ações adquirem para eles no cotidiano, em razão de implicações simbólicas, relacionais e materiais, e considerá-los protagonistas do próprio cuidado, exige ampliação dos horizontes da racionalidade que orienta tecnologias e agentes das práticas. Implica também em conhecer o lugar que nossas práticas podem ocupar no projeto de cuidado de usuários e famílias.

O desafio é compreender a diferença entre a ciência médica e a arte de cuidar e de curar, o que significa distinguir a diferença existente entre o saber das coisas em geral e a concreta aplicação desse saber ao caso singular. Isto significa a construção, junto com a pessoa cuidada, do seu projeto de cuidado e, consequentemente, a construção do saber em enfermagem incluindo a experiência vivida dos que trabalham e dos que usam os serviços de saúde.

Concluímos que a reconstrução das práticas em enfermagem e na saúde, na perspectiva de combater o descuidado, pressupõe assumir o cuidado como cerne da formação e da prática nesse campo, além de investimentos no financiamento do SUS, para que seu projeto tenha o sucesso prático possível e esperado.

\section{Colaborações:}

1. concepção, projeto, análise e interpretação dos dados: Fernanda Carneiro Mussi e Cristina Maria Meira de Melo;

2. redação do artigo e revisão crítica relevante do conteúdo intelectual: Fernanda Carneiro Mussi e Cristina Maria Meira de Melo;

3. aprovação final da versão a ser publicada: Fernanda Carneiro Mussi e Cristina Maria Meira de Melo.

\section{Referências}

1. Ayres JRCM. Care, (the) human being and health practices. Saúde soc. 2004;13(3):16-9.

2. Ayres JRCM. Subject, intersubjectivity and health practice. Ciênc saúde coletiva. 2001;7(1):63-72.

3. Lucena AF, Paskulin LMG, Souza MF, Gutiérrez MGR. Health care models and the building of nursing knowledge and practice. Rev Esc Enferm USP. 2006;40(2):292-8.

4. Puschel VAA, Ide CAC, Chaves EC. Clinical and psychosocial models of attention to the individual and the family in home care - conceptual frameworks. Rev Esc Enferm USP. 2006;40(2):261-8.

5. Ide CAC. A coordenação do processo de cuidar. In: Ide CAC, Domenico EBL, editoras. Ensinando e aprendendo um novo estilo de cuidar. São Paulo: Atheneu; 2001. p. 153-64.

6. Rodrigues AM. Poder e cultura nas organizações. Rev Paul Enferm. 1991;10(2):67-72.

7. Menzies IEP. A case-study in the functioning of social systems as a defence against Anxiety: a report on a study of the nursing service of a general hospital. Human Relations [Internet]. 1960 [cited 2009 July 31];13:95-121. Available from: http://hum. sagepub.comDoi:10.1177/001872676001300201

8. Mussi FC. Desconforto, modelo biomédico e enfermagem: reflexões com base na experiência de homens infartado. Acta Paul Enferm. 2003;16(3):88-96.

9. Mussi FC. Comfort and hospital practice: an analysis from the historical perspective of the concept of comfort in nursing. Acta Paul Enferm. 2005;18(1):72-81. 
10. Souza ECF, Vilar RLA, Rocha NSPD, Uchoa AC, Rocha PM. Primary health care access and receptivity to users: an analysis of perceptions by users and health professionals. Cad Saúde Pública. 2008;24(supl 1):S100-10.

11. Melo CM. Editorial. Desafios contemporâneos sobre trabalho e formação da enfermeira no Brasil. Rev baiana enfermagem. 2016;30(2):3-5.
12. Kruse MHL. Is it possible to view nursing education differently? Esc Anna Nery Rev Enferm. 2008;12(2):348-52.

Recebido: 25 de fevereiro de 2018

Aprovado: 6 de agosto de 2018

Publicado: 25 de outubro de 2018

A Revista Baiana de Enfermagem utiliza a Licença Creative Commons - Atribuição-NãoComercial 4.0 Internacional. https://creativecommons.org/licenses/by-nc/4.0/ Este artigo é de acesso aberto distribuído sob os termos da Licença Creative Commons (CC BY-NC). Esta licença permite que outros remixem, adaptem e criem a partir do seu trabalho para fins não comerciais. Embora os novos trabalhos tenham de lhe atribuir o devido crédito e não possam ser usados para fins comerciais, os usuários não têm de licenciar esses trabalhos derivados sob os mesmos termos. 